\title{
Pharmacogenetics in multiple sclerosis: the long and winding road ahead of us
}

\author{
Farmacognética na esclerose múltipla: a longa e tortuosa estrada à nossa frente
}

Yara Dadalti Fragoso

\author{
Universidade Metropolitana \\ de Santos, Departamento de \\ Neurologia, Santos SP, Brasil. \\ Correspondence: \\ Yara Dadalti Fragoso; \\ Avenida Conselheiro Nebias, 536; \\ 11045-002 Santos SP, Brasil; \\ E-mail:yara@bsnet.com.br \\ Conflict of interest: \\ There is no conflict of interest to \\ declare. \\ Received 20 September 2018; \\ Accepted 27 September 2018.

\section{(cc) BY}

$\mathrm{T}$

he ideal drug has the highest efficacy, the lowest rate of adverse events and a very low cost. Unfortunately, most diseases are not treated with the "ideal drug" and multiple sclerosis (MS) is an important example of this situation. Therapy for MS has unique characteristics, as we do not increase the dose of disease-modifying drugs (DMDs), change drug schedules, or combine different drugs for better results. When a DMD does not provide the optimal response, it is exchanged for another one, and this can happen as many times as the physician in charge deems necessary. Beyond the obvious frustration for the patient, the cost of such a trial-and-error approach is high. If we could use the genetic makeup of a patient to choose the perfect medication for that individual, we could aim for the ideal drug for that particular patient with MS. Pharmacogenetics is the study of how genetic differences can affect variation in responses to therapy, thus allowing us to achieve "personalized medicine" through optimal decisions ${ }^{1}$. Using pharmacogenetics, we could treat each patient with MS with the ideal drug for maximal benefit.

In the present issue of Arquivos de Neuro-Psiquiatria, Werneck et al. ${ }^{2}$ discuss the personal data of 87 patients with MS, genotyped for HLA-DRB1, HLA-DPB1, HLA-DQB1, HLA-A, HLA-B and HLA-C alleles. They analyzed the neurological disability outcomes of these patients in relation to their genetic background and the use of specific DMDs. Unfortunately, these researchers found only a few relationships between the patients' HLA profile and their response to drugs. Their conclusion was that there might be a relationship between the HLA profile and the effect of DMDs on some HLA class I and II alleles in some patients. They advised caution in interpreting their results since there was a limited number of patients with some types of HLA and DMDs.

There are few studies on the pharmacogenetics of MS $34,4,5,6,7,8,9$. The specific response of an individual patient to any of the DMDs remains largely unpredictable, and a trial-and-error approach is the rule when deciding on treatment regimens. It is imperative that we continue research to enable us to predict the optimal benefit-to-risk profile of an individual patient with $\mathrm{MS}^{10}$. With more data on the matter, the decision-making process would be greatly facilitated, and the patient would receive a personalized optimal treatment early on in the disease pro$\operatorname{cess}^{11}$. There is, however, a long and winding road ahead of us regarding expectations, associations, predictions and recommendations in pharmacogenetics for patients with MS. 
1. Limdi NA, Veenstra DL. Expectations, validity, and reality in pharmacogenetics. J Clin Epidemiol. 2010 Sep;63(9):960-9. https://doi.org/10.1016/j.jclinepi.2009.09.006

2. Werneck LC, Lorenzoni PJ, Kay CS, Scola RH. Multiple sclerosis: disease modifying therapy and the human leukocyte antigen. Arq Neuropsiquiatr. 2018;76(10):697-704. https://doi.org/10.1590/0004-282X20180103

3. Comabella M, Fernández-Arquero M, Río J, Guinea A, Fernández $\mathrm{M}$, Cenit MC et al. HLA class I and II alleles and response to treatment with interferon-beta in relapsing-remitting multiple sclerosis. J Neuroimmunol. 2009 May;210(1-2):116-9. https://doi.org/10.1016/j.jneuroim.2009.01.012

4. Grossman I, Avidan N, Singer C, Goldstaub D, Hayardeny $L$, Eyal $E$ et al. Pharmacogenetics of glatiramer acetate therapy for multiple sclerosis reveals drug-response markers. Pharmacogenet Genomics. 2007 Aug;17(8):657-66. https://doi.org/10.1097/FPC.0b013e3281299169

5. Fernández O, Fernández V, Mayorga C, Guerrero M, León A, Tamayo JA et al. HLA class II and response to interferon-beta in multiple sclerosis. Acta Neurol Scand. 2005 Dec;112(6):391-4. https://doi.org/10.1111/j.1600-0404.2005.00415.x

6. Samadzadeh S, Tabibian E, Sabokbar T, Shakoori A, Dehgolan SR, Armaki SA et al. HLA-DRB1 does not have a role in clinical response to interferon-beta among Iranian multiple sclerosis patients. J Neurol Sci. 2015 May;352(1-2):37-40. https://doi.org/10.1016/j.jns.2015.03.004

7. Søndergaard HB, Petersen ER, Magyari M, Sellebjerg F, Oturai AB. Genetic burden of MS risk variants distinguish patients from healthy individuals but are not associated with disease activity. Mult Scler Relat Disord. 2017 Apr;13:25-7. https://doi.org/10.1016/j.msard.2017.01.015

8. Kulakova O, Bashinskaya V, Kiselev I, Baulina N, Tsareva E, Nikolaev $R$ et al. Pharmacogenetics of glatiramer acetate therapy for multiple sclerosis: the impact of genome-wide association studies identified disease risk loci. Pharmacogenomics. 2017 Nov;18(17):1563-74. https://doi.org/10.2217/pgs-2017-0058

9. Ross CJ, Towfic F, Shankar J, Laifenfeld D, Thoma M, Davis M et al. A pharmacogenetic signature of high response to Copaxone in latephase clinical-trial cohorts of multiple sclerosis. Genome Med. 2017 May;9(1):50. https://doi.org/10.1186/s13073-017-0436-y

10. Grossman I, Knappertz V, Laifenfeld D, Ross C, Zeskind B, Kolitz S et al. Pharmacogenomics strategies to optimize treatments for multiple sclerosis: insights from clinical research. Prog Neurobiol. 2017 May;152:114-30. https://doi.org/10.1016/j.pneurobio.2016.02.001

11. Tsareva E, Kulakova O, Boyko A, Favorova O. Pharmacogenetics of multiple sclerosis: personalized therapy with immunomodulatory drugs. Pharmacogenet Genomics. 2016 Mar;26(3):103-15. https://doi.org/10.1097/FPC.0000000000000194 